\title{
EXCLUSION FROM ENTERTAINMENT AND LEISURE VENUES: CAN'T WE PLAY, TOO?
}

\author{
Geraldine Rosa Henderson, Rutgers Business School-Newark and New Brunswick, USA \\ Jerome D. Williams, Rutgers Business School-Newark and New Brunswick, USA
}

\begin{abstract}
The purchasing power of historically invisible groups is growing and yet we continue to see instances of entertainment and leisure venues either outright denying access to them and/or at least degrading the service that they receive. We study this and other such discrimination and injustice against groups based on gender, religion, skin tone, body image, weight, sexual orientation, language, disability, and other demographic markers (Walsh 2009). We provide a historical perspective, discuss our qualitative methodology, present our findings, and conclude with some recommendations for marketers and researchers in supporting the transformation of the lives of consumers in oppressed groups and segments from positions of being discriminated against and experiencing marketplace injustice to a position of fair and equitable treatment in a marketplace reflecting social justice.
\end{abstract}

We have developed a theoretical perspective on why these injustices are differentially perceived across groups. Thus, our research questions are as follows: To whom does Entertainment and Leisure Marketplace Discrimination occur and how? Do members of traditionally dominant groups and traditionally marginalized groups differ in the perceptions of Marketplace Discrimination? How are service provider reactions to allegations of Marketplace Discrimination perceived by members of marginalized groups?

We collected primary data in the form of depth interviews and drew heavily from extant literature. Respondents represented various ethnoracial backgrounds, genders, sexual orientations, religions, etc. (cf. Motley and Henderson 2008; Motley, Henderson, and Baker 2003; Spiggle 1994). The coauthors and student collaborators interviewed people identified in multiple ways. The interviews were either conducted face-to-face or over the telephone, via the internet (e.g., Skype). Each interview was audio and/or video-taped and were between 40 and 90 minutes long. Interpretations of emergent themes were derived directly from interview transcripts, interviewer notes and the extant literature. The themes were independently developed by the co-authors and their research assistants, and while the labels differed, the interpretations overlapped.

We believe that the emergent themes from our data are best captured by our theoretical framework: liberation psychology. At its core, liberation psychology concerns the interaction between individuals and society (McKown 2005). Liberation psychology assumes that oppression often includes a tacit acceptance of inequities by oppressors and oppressed. From this perspective, oppression reflects lack of awareness of societal conditions that maintain oppression. The key to overcoming oppression is thus the development of "critical consciousness" on the part of oppressed people, or an awareness of social and economic contradictions, particularly the conditions of social inequality. Adams, O'Brien, and Nelson (2006) focus on three central tenets of a Liberation Psychology analysis: adopting the perspective of the oppressed, recovering historical memory, and de-ideologizing everyday experience (Martın-Baro, 1994, p. 30).

Liberation Psychology provides the perfect theoretical base to account for our marketplace discrimination data. We maintain that if more entertainment and leisure marketers adopted the perspective of the oppressed, they would be less likely to create/tolerate such circumstances. In addition, to the extent that marketers are able to Recover Historical Memory they would understand the context in which their traditionally marginalized customers put what they may believe are innocent mistakes. Lastly, by moving past feelings of guilt and confronting the issues head on, owners and managers of entertainment venues will be able to have a productive dialog with consumers about what constitutes fair treatment.

References available upon request.

Proceedings of AMS' World Marketing Congress Cultural Perspectives in Marketing (C 2012 